\title{
UNJUK KERJA DAN PEMANFAATAN INVERTER SEBAGAI PENGENDALI KECEPATAN MOTOR INDUKSI 3 PHASA
}

\author{
Oleh : \\ Anton, Tuti Angraini \\ Staf Pengajar Jurusan Teknik Elektro Politeknik Negeri Padang \\ anton.poli2000@gmail.com
}

\begin{abstract}
The Induction motors are found in industrial and domestic environments because of low cost of operation including, induction motors are widely used induction motor 1 phase and 3 phase. During operation of induction motors generally used at normal speed, but the specific purpose induction motors operated with variable speed. In order to obtain varying motor speed can be controlled using the inverter. The use of inverters here to give supplay voltage AC induction motor in which the magnitude of the frequency can be varied. Setting frequency of the inverter utilizing method pulse with modulation (PWM). The circuit used to build PWM, using Insulated Gate Bipolar Transistor (IGBT) technology. Values obtained variable frequency ranging from $4 \mathrm{~Hz}$ to $50 \mathrm{~Hz}$, and acquired motor speed ranging from $12 \mathrm{rpm}$ up to $1390 \mathrm{rpm}$.
\end{abstract}

Keywords : inverter, PWM, IGBT, induction motors.

\section{PENDAHULUAN}

Motor induksi merupakan motor listrik arus bolak balik (ac) yang paling luas digunakan Penamaannya berasal dari kenyataan bahwa motor ini bekerja berdasarkan induksi medan magnet stator ke statornya, dimana arus rotor motor ini bukan diperoleh dari sumber tertentu, tetapi merupakan arus yang terinduksi sebagai akibat adanya perbedaan relatif antara putaran rotor dengan medan putar (rotating magnetic field) yang dihasilkan oleh arus stator.

Motor induksi sangat banyak digunakan dalam kehidupan sehari-hari baik di industri maupun di rumah tangga. Motor induksi yang umum dipakai adalah motor induksi 3 phasa dan motor induksi 1 phasa. Motor induksi 3 phasa dioperasikan pada sistem tenaga 3 phasa dan banyak digunakan di dalam berbagai bidang industri, sedangkan motor induksi 1 phasa dioperasikan pada sistem tenaga 1 phasa yang banyak digunakan terutama pada penggunaan untuk peralatan rumah tangga seperti kipas angin, lemari es, pompa air, mesin cuci dan sebagainya karena motor induksi 1 phasa mempunyai daya keluaran yang rendah, hal ini dikarenakan keunggulan yang dimiliki oleh motor AC tersebut, dalam hal harga, ukuran, berat, konstruksi, perawatan, dan efisiensi. Selain mempunyai kelebihan motor induksi juga mempunyai kekurangan dalam hal torsi dan pengaturan kecepatannya. Namun setelah ditemukannya inverter, kecepatan motor induksi dapat diatur dalam jangkauan yang sangat lebar [1]. Secara konvensional motor induksi dioperasikan pada kecepatan yang tetap sesuai dengan frekuensi sumber tegangan serta jumlah kutub dari motor induksi. Pengaturan kecepatan pada motor induksi jauh lebih sulit dibandingkan dengan motor DC karena tidak ada hubungan yang linier antara arus motor dan torsi yang 
dihasilkan seperti pada motor DC.

Suatu metode yang kemudian disebut sebagai vector control digunakan untuk mengatur kecepatan motor induksi pada rentang kecepatan yang besar serta presisi dan respon yang cepat. Pada vector control, pengaturan motor induksi ini telah diubah seperti pengaturan motor arus searah, sehingga dalam pengaturan motor induksi dapat digunakan berbagai kontroler seperti pada pengaturan kecepatan motor arus searah. Pengaturan kecepatan motor induksi dengan metode vector control memerlukan inverter untuk memberikan tegangan pada motor. Pada beberapa paper telah diteliti pengaturan kecepatan motor induksi dengan menggunakan switching inverter dimana tegangan yang diberikan pada motor induksi mempunyai perubahan hanya berkisar pada satu, nol dan negatif satu

Motor AC 3 phasa dapat dioperasikan dan dikontrol kecepatannya, melalui sumber AC 1 phasa di mana suatu sinyal masukan AC 1 phasa tersebut, dikonversi menjadi tegangan DC link dengan jembatan penyearah terkontrol dan filter, hasil yang didapatkan berupa tegangan DC. Tegangan DC tersebut diubah kembali menjadi tegangan output tiga-fasa, dengan frekuensi yang dapat dikendalikan, oleh phasa tiga-switching inverter jembatan. Amplitudo tegangan link yang diberikan oleh jembatan penyearah dan filter dikendalikan oleh sebuah sinyal kontrol yang juga menetapkan frekuensi dari sinyal keluaran 3 tahap yang disediakan oleh jembatan inverter switching. Sebuah rangkaian bertindak cepat membatasi saat ini memantau terpisahkan dari link tegangan DC selama interval waktu terpilih untuk menyesuaikan pengoperasian frekuensi jembatan switching jika melebihi integral ambang batas [2]

\section{TINJAUAN PUSTAKA}

\section{Motor Induksi}

Motor induksi bekerja berdasarkan induksi elektromagnetik dari kumparan stator kepada kumparan rotornya. Garis-garis gaya fluks yang diinduksikan dari kumparan stator akan memotong kumparan rotornya sehingga timbul emf (ggl) atau tegangan induksi dan karena penghantar (kumparan) rotor merupakan rangkaian yang tertutup, maka akan mengalir arus pada kumparan rotor. Penghantar (kumparan) rotor yang dialiri arus ini berada dalam garis gaya fluks yang berasal dari kumparan stator sehingga kumparan rotor akan mengalami gaya Lorentz yang menimbulkan torsi yang cenderung menggerakkan rotor sesuai dengan arah pergerakan medan induksi stator. Pada rangka stator terdapat kumparan stator yang ditempatkan pada slot-slotnya yang dililitkan pada sejumlah kutup tertentu. Jumlah kutup ini menentukan kecepatan berputarnya medan stator yang terjadi yang diinduksikan ke rotornya. Makin besar jumlah kutup akan mengakibatkan makin kecilnya kecepatan putar medan stator dan sebaliknya. Kecepatan berputarnya medan putar ini disebut kecepatan sinkron. Besarnya kecepatan sinkron ini adalah sebagai berikut [3]

$$
\begin{aligned}
\omega_{\text {sink }} & =2 \pi \mathrm{f} \text { (listrik, rad } / \mathrm{dt}) \\
& =2 \pi \mathrm{f} / \mathrm{P}(\text { mekanik, } \mathrm{rad} / \mathrm{dt})
\end{aligned}
$$

atau:

Ns $=60 . \mathrm{f} / \mathrm{P}$ (putaran/menit, rpm)

dimana :

$\mathrm{f}=$ frekuensi sumber $\mathrm{AC}(\mathrm{Hz})$

$\mathrm{P}=$ jumlah pasang kutup

Ns dan $\omega_{\text {sink }}=$ kecepatan putaran sinkron medan magnet stator

Prinsip kerja motor induksi berdasarkan macam phasa sumber tegangannya dapat dijelaskan lebih lanjut sebagai berikut. 


\section{Sumber 3 Phasa}

Sumber 3 phasa ini biasanya digunakan oleh motor induksi 3 phasa. Motor induksi 3 phasa ini mempunyai kumparan 3 phasa yang terpisah antar satu sama lainya sejarak $120^{\circ}$ listrik yang dialiri oleh arus listrik 3 phasa yang berbeda phasa $120^{\circ}$ listrik antar phasanya, sehingga keadaan ini akan menghasilkan resultan fluks magnet yang berputar seperti halnya kutup magnet aktual yang berputar secara mekanik. Bentuk gambaran sederhana hubungan kumparan motor induksi 3 phasa dengan dua kutup stator diperlihatkan pada gambar 1 [4]

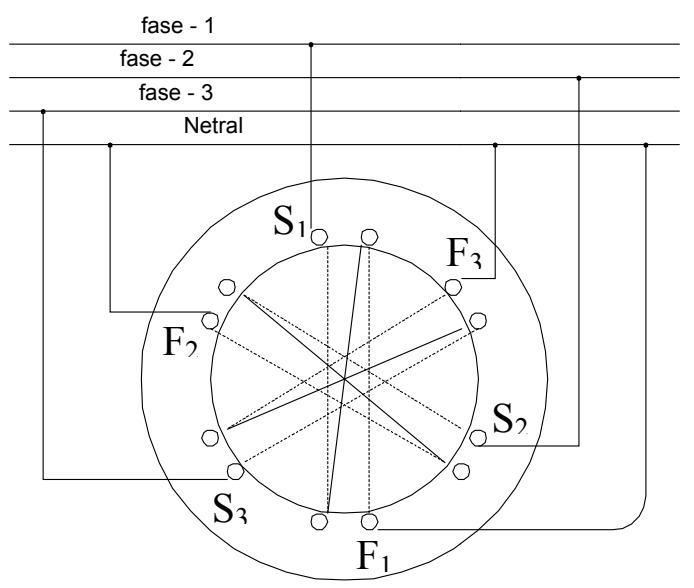

Gambar 1 Bentuk hubungan kumparan motor induksi 3 phasa dengan dua kutup stator

Bentuk gambaran fluk yang terjadi pada motor induksi 3-fasa diperllihatkan pada gambar 2 (fluks yang terjadi pada kumparan 3 phasa diasumsikan sinusoidal seperti yang diperlihatkan pada gambar $2 \mathrm{a}$ dengan arah fluks positif seperti gambar $2 b$ )

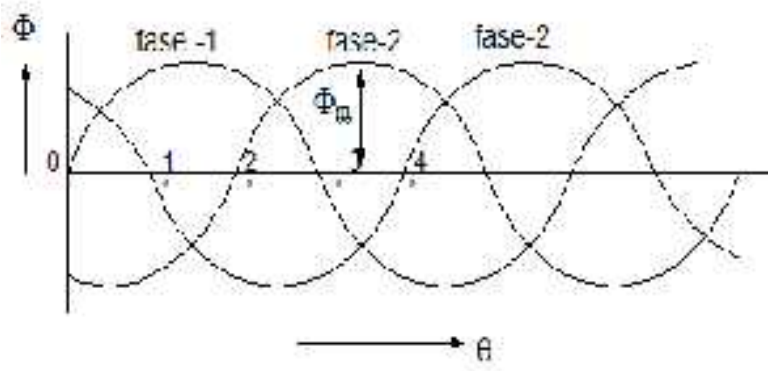

(a)

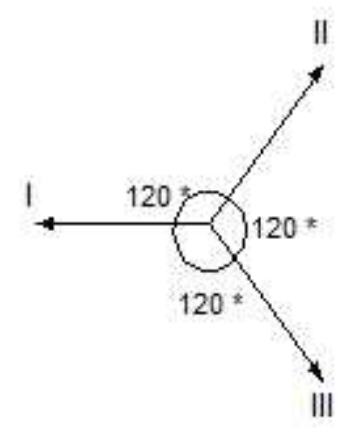

(b)

Gambar 2 Fluks yang terjadi pada motor induksi 3 phasa

\section{Memilih Motor Listrik}

Setiap motor listrik sebagai alat penggerak sudah mempunyai klasifikasi tertentu sesuai dengan maksud penggunaannya menurut kebutuhan yang diinginkan. Klasifikasi tiap motor listrik bisa dibaca pada papan nama (name plate) yang dipasang padanya sehingga untuk berbagai keperluan bisa dipilih motor yang sesuai.

Di dalam pemakaian sederhana, klasifikasi motor hanya dikenal menurut:

a. Tenaga output motor (HP).

b. Sistem tegangan (searah, bolak-balik, ukurannya, phasanya).

c. Kecepatan motor (rendah, sedang, tinggi). 


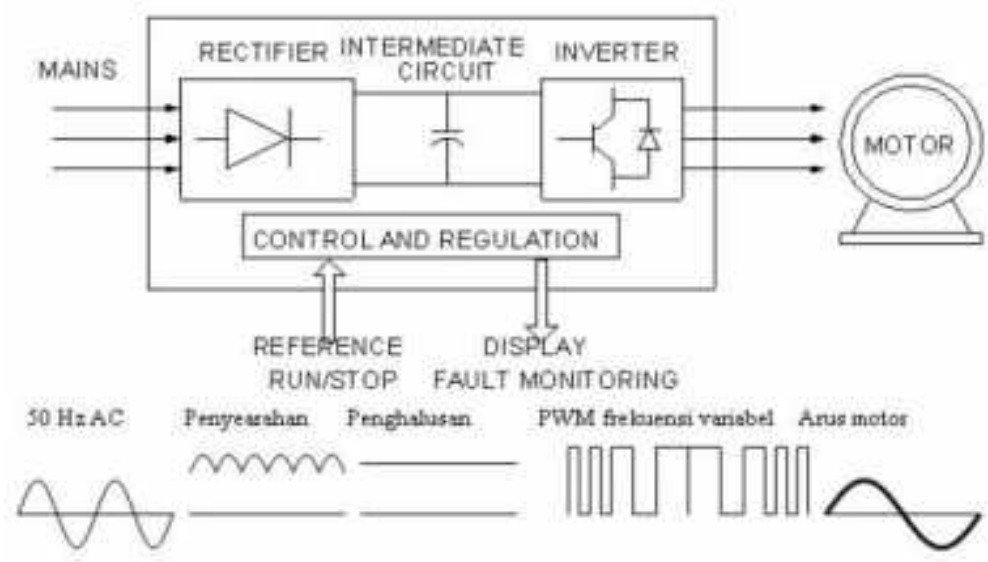

Gambar 3 Prinsip dasar rangkaian inverter

\section{INVERTER}

Inverter, merupakan rangkaian elektro- nika daya yang dapat digunakan untuk merubah tegangan searah (DC) ke suatu bentuk tegangan bolak-balik (AC). Ada beberapa jenis inverter yang ada sekarang ini, dari yang hanya Menghasilkan tegangan keluaran kotak bolakbalik (push-pull inverter) sampai yang sudah bisa menghasilkan tegangan sinus murni (tanpa harmonisa). Jenis Inverter yang sering digunakan adalah inverter satu phasa dan tiga phasa

Ada beberapa cara teknik kendali yang digunakan agar inverter mampu menghasilkan sinyal sinusoidal, yang paling sederhana adalah dengan cara mengatur keterlambatan sudut penyalaan inverter. Teknik yang sering digunakan adalah dengan modulasi lebar pulsa (PWM). Sinyal kontrol penyaklaran di dapat dengan cara membandingkan sinyal referensi (sinusoidal) dengan sinyal carrier (digunakan sinyal segitiga). Dengan cara ini frekuensi dan tegangan fundamental mempunyai frekuensi yang sama dengan sinyal referensi sinusoidal.

Penggunaan inverter untuk pengendalian kecepatan motor Induksi, menggunakan inverter PWM mempunyai kelebihan, yaitu mampu menggerakkan motor induksi dengan putaran yang stabil. Selain itu apabila pembangkitan sinyal PWM dilakukan secara digital akan diperoleh unjuk kerja sistem yang baik karena lebih kebal terhadap perubahan derau. Adapun komponen utama yang sering digunakan adalah:

\section{Perubahan Frekuensi dan Tegangan}

Sebuah variabel frekuensi drive jenis tertentu disesuaikan kecepatan dengan drive. Variabel-frekuensi drive juga dikenal sebagai frekuensi disesuaikan drive, variabel-speed drive (VSD), AC drive, microdrives atau inverter drive. Karena tegangan bervariasi bersama dengan frekuensi, ini kadang-kadang juga disebut $\mathrm{VV}^{-} \mathrm{VF}$ (variabel Voltage Variable Frequensi) drive.

Variabel-drive frekuensi digunakan secara luas. Sebagai contoh, dalam sistem ventilasi untuk gedung, variabel-frekuensi pada pengaturan putaran motor dapat menghemat energi dengan pengaturan volume perpindahan udara ke sistem yang disesuaikan dengan permintaan. Variable Frekuensi Drive digunakan pada control AHU, Elevator, Lift, Hoist, Mesin-mesin Textile, Conveyor, mesin-mesin Textile, CNC, Mesin Cuci Industri. Power masukan tegangan RST 


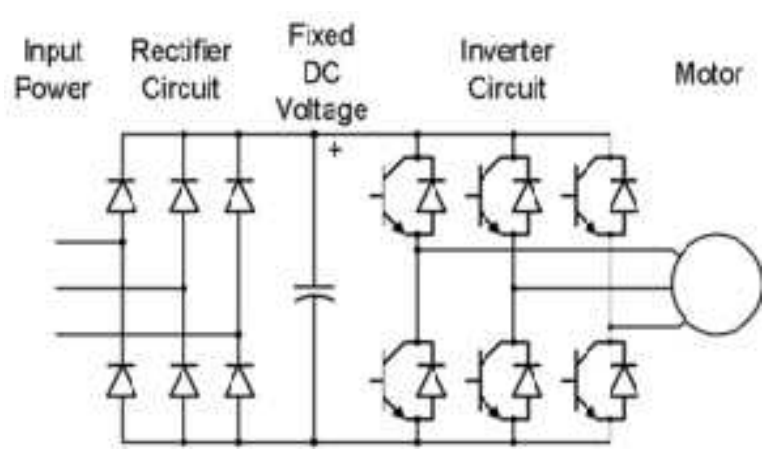

Gambar 4 Prinsip dasar rangkaian system control inverter IGBT

berbentuk gelombang Sinus (AC) dengan frekwensi tetap ( $50 / 60 \mathrm{~Hz}$ ), diubah menjadi gelombang DC oleh Dioda penyearah, area ini dinamakan DC-BUS.

Gelombang DC kemudian dirubah kembali ke gelombang AC kembali dengan frekwensi yang dapat diatur oleh perangkat pembolak-balik inverting. Modul ini dinamakan modul Transistor, yang dikenal dengan modul IGBT (Insulated Gate Bipolar Transistor). Motor yang digunakan dalam sistem VFD biasanya merupakan motor induksi 3 phasa. Beberapa jenis phasa tunggal motor dapat digunakan, tetapi 3 phasa motor biasanya lebih tepat. Berbagai jenis motor sinkron menawarkan keuntungan dalam beberapa situasi, tetapi motor induksi yang cocok untuk sebagian besar tujuan dan biasanya pilihan yang paling ekonomis. Motor yang dirancang untuk kecepatan tetap dengan tegangan utama operasi yang sering digunakan, tetapi perangkat tambahan tertentu ke desain motor standar menawarkan keandalan yang lebih tinggi dan lebih baik kinerja VFD.

\section{Inverter Dengan IGBT}

Sebagai jenis bahan semikonduktor bekerja berdasarkan pensaklaran (switching) yang telah banyak diperkenalkan, ini harus segera diterapkan pada rangkaian inverter di semua tegangan dan arus yang sesuai peringkat untuk kebutuhan perangkat yang tersedia, seperti gambar [5].

\section{HASIL DAN PEMBAHASAN}

Berdasarkan hasil pengukuran yang dilakukan pada penelitian ini, menggunakan Inverter, diperlihatkan bahwa setiap kenaikan frekuensi yang diatur mengakibatkan perubahan pada kecepatan motor induksi. Berikut ini hasil pengukuran hubungan antara frekuensi dengan kecepatan motor.

Tabel 1 Hasil Pengukuran Hubungan Frekuensi dengan Kecepatan Motor.

\begin{tabular}{|c|c|c|}
\hline NO & $\begin{array}{c}\text { FREKUENSI } \\
(\mathrm{Hz})\end{array}$ & $\begin{array}{c}\text { KECEPATAN } \\
(\mathrm{rpm})\end{array}$ \\
\hline 1 & 2 & 0 \\
\hline 2 & 4 & 120 \\
\hline 3 & 8 & 240 \\
\hline 4 & 12 & 360 \\
\hline 5 & 16 & 480 \\
\hline 6 & 20 & 600 \\
\hline 7 & 24 & 720 \\
\hline 8 & 28 & 832 \\
\hline 9 & 32 & 952 \\
\hline 10 & 36 & 1072 \\
\hline 11 & 40 & 1192 \\
\hline 12 & 44 & 1312 \\
\hline 13 & 48 & 1432 \\
\hline 14 & 50 & 1492 \\
\hline
\end{tabular}


Apabila dilihat secara seksama bahwa hubungan tersebut hampir linier, selanjutnya hubungan antara frekuensi variabel dengan kecepatan motor diperlihat pada gambar 5 memperlihatkan hasil pengukuran, hubungan antara frekuensi variabel terhadap tegangan yang dibangkItkan, seperti pada tabel 2 dibawah ini:

Tabel 2 Hasil Pengukuran Hubungan Frekuensi dengan Tegangan Motor

Dari data tabel diatas dapat digambarkan dalam bentuk grafik sebagaimana diperlihatkan pada gambar 6 .

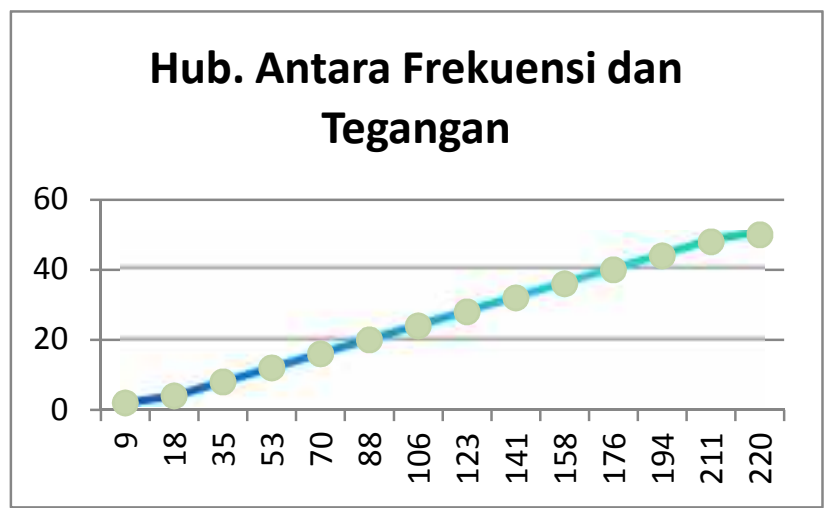

Gambar 6 Hubungan antara Frekuensi dan Tegangan

\section{KESIMPULAN}

Berdasarkan hasil penelitian, merujuk kepada teori dasar dan analisa diatas dapat diambil kesimpulan sebagai berikut:

1. Penggunaan invertir tipe TRAINER BOARD LS-XGT -090B untuk aplikasi pengontrol kecepatan motor induksi sangat baik .

2. Karakteristik hubungan antara tegangan yang dihasilkan dan perubahan frekuensi, menghasilkan putaran motor yang linier.

3. Penggunaan teknologi Semikonduktor IGBT sangat cocok diaplikasikan untuk mendapatkan rangkaian inverter.

pengukuran tegangan keluar pada inverter untuk keperluan supplay Motor Induksi, apabila dilakukan perubahan terhadap frekuensi, berikut ini 


\section{DAFTAR PUSTAKA}

[1] Albert Paul Malvino, Ph.D Prinsipprinsip Elektronika jilid II Penerbit Erlangga Jakarta, 1990.

[2] Frand D. Petruzella, Elektronik Industri, Andi Yogyakarta, 2001.

[3] Hasyim Asy'ari, Aris Rakhmadi, Pengendalian Kecepatan Putar Motor induksi 1 phasa, jurnal teknik elektro dan komputer emitor vol. 4, no. 1, Surakarta, 2004.

[4] Sigit Budhi Santoso, Aris Rakhmadi, Pengendalian Kecepatan Motor Induksi Melalui Inverter Altivar 18Berdasarkan Kendali Fuzi Berbasis PLC, Teknik Elektro Universitas Gadjah Mada, Yogyakarta, 2003.

Vithayathil Yoseph, Power

[5] Electronics Prinsip and Aplications, McGraw-Hill, inc, New York, 1995

Buku panduan Pemrograman PLC

[6] Trainer Option Inverter LS-XGT09903B, LS Industrial System, Jakarta, 2009. 
ISSN :2085-6989 